\title{
Balkan briefing (part 4). Kosovo refugees in the North West region of the United Kingdom
}

\author{
Iqbal Sram, David Ward \\ "Once we had a country and we thought it fair \\ Look in the atlas and you'll find it there \\ We cannot go there now, my dear, we cannot go there now" \\ W H Auden
}

The unstable political situation in the former Yugoslavia has resulted in inter-ethnic conflict with profound economic, social and human rights consequences. It led to a major military intervention by North Atlantic Treaty Organisation (NATO) forces. A large proportion of the Kosovars were forced to abandon their homes and seek refuge in Macedonia and Albania.

The government of Macedonia was very worried that the large number of Kosovor refugees in their country might destablise the country's delicate political balance. This led to pressure on the European Union countries to make adequate arrangements to admit substantial number of refugees from Kosovo into the European Union countries.

The United Kingdom government agreed to take in a unspecified number of refugees. In the event 4346, refugees were admitted into the United Kingdom under the United Nations High Commission for Refugees (UNHCR) Humanitarian Evacuation Programme. Of this total 2400 were accommodated in the North West region of the United Kingdom. The general plan was that the new arrivals should be looked after in parts of the country other than the south east part of the United Kingdom. The government was of the view that the south east part of the country had already taken a large number of ad hoc asylum seekers.

\section{National arrangements}

In the United Kingdom the responsibility for coordinating contingency arrangements for any influx of refugees lies with the Home Office. On this occasion the Home Office charged the Refugee Council with setting up and running whatever reception facilities may be necessary, including transport from the port of entry. The Refugee Council was chosen as it has the expertise in the needs of the refugee population and as an independent body that campaigns for the social and political rights of the refugee community in the United Kingdom.

The two United Kingdom government departments with an important role in providing support to the new arrivals are the Department of Health and the Department of Environment, Transport and Regions (DETR). The DETR is responsible for the actions of the local authorities, which in the United Kingdom are local democratic bodies. The local authorities are responsible for the public provision of housing, primary and secondary education services and essential social services. The United Kingdom local authorities have a representative body called the Local Government Association. This body generally represents the local authority perspective on public policy to the DETR

\section{The Department of Health}

The role of the Department of Health in the arrangements to provide healthcare to the new arrivals was to determine rules for entitlement to healthcare and to assume a leadership role in ensuring that the new arrivals received care that was of high professional and technical standards.

The Department of Health was expected to: - Determine the entitlement for health care services

- Make arrangements for the delivery of health care services

- Make arrangements for special needs cases

- Put forward any amendments required to the existing domestic rules or regulations

- Provide guidance for doctors, hospitals, local authorities, other government departments and voluntary organisations on health care entitlement

- Nominate a single point of contact with telephone, fax and e-mail for all enquiries

The Department of Health executed its responsibility via its Emergency Planning Co-ordination Unit (EPCU). The EPCU is charged with ensuring that the Department of Health responds proactively to emergency situations whenever there is a threat to health or safety of a section of the local populations. To meet its obligations the EPCU issued a Health Service Circular- Kosovo: Health and Social Care for Refugees. The Health Service Circulars are used by the Department of Health to direct the healthcare system in the United Kingdom to ensure that the Department of Health policy objectives are met in a timely manner. The Health Service Circular was directed at:

- Health authorities

- National Health Service Trusts

- Local government bodies (these take a number of different forms in the United Kingdom)

The Health Service Circular stated that the United Kingdom government was committed to accept refugees from Kosovo as a contribution to the humanitarian relief programme being organised by the UNHCR. People arriving under the UNHCR programme would be given 12 months leave to remain in the United 
Kingdom in the first instance. They would have the right to obtain employment in the United Kingdom and would also be entitled to receive social assistance made available by the United Kingdom government to eligible United Kingdom nationals. The Health Service Circular also explicitly stated that the Government's intention was that the health and social care needs of refugees from Kosovo should be assessed and met as if they were ordinarily resident in the United Kingdom. The Health Service Circular gave a clear lead to health professionals on the value of interagency cooperation at national, regional and local level.

The response in the North West region of the United Kingdom

The United Kingdom has 11 health regions. Three of these health regions (Scotland, Wales and Northern Ireland) have a distinct relationship with Department of Health. The remaining eight health regions are the English regions. The North West part of England has a population of about 6.5 million with two large cities of Manchester and Liverpool. Manchester also has the region's major international airport.

The North West region has 16 health authorities. These authorities are charged with the task of meeting the health needs of their local populations. They employ professionals with expertise in assessing population health needs. The health authorities have devolved budgets that they deploy to commission health care from state and private providers. The main service agreements for healthcare provision are with the state providers, the National Health Service Trusts.

There are 48 local authorities in the North West. The local authorities are democratic bodies that are expected to act within the powers conferred to them by the United Kingdom Parliament, the supreme legislative body in the United Kingdom. The local authorities have duties to fulfil a large number of civic functions. In the context of the refugee population the relevant functions relate to social services, housing and education (primary and secondary).

\section{The planning in the North West Region} for reception and care of refugees

The planning for the reception and care of refugees in the North West region was led by the Health Emergency Planning Advisor (HEPA). The HEPA has very close day to day relationship with the EPCU and reports to the Regional Director of Public Health. The HEPA is charged with the responsibility of building and maintaining the region's capacity and capability to respond to situations that can pose a threat to public safety and health. The HEPA is supported in his work by the Regional Epidemiologist with an expertise in communicable disease control. The HEPA also has ready access to advice on environmental hazards and in addition can readily access generic public health advice.

In their day to day work the HEPA has established effective links with the agencies that would have a role in emergency situations. The local authorities, the health authorities, the police, the fire service, the ambulance service, the Environment Agency, and the hospital service are among the bodies with whom the HEPA has close relationships. These relationships provided the Regional Director of Public Health and EPCU with an easy and rapid access to the main agencies that have resources to meet the health and social care needs of the refugees at the local level.

The HEPA convened meetings at a sub regional level of the key agencies to agree a basic operational framework to cater for the needs of the refugees. These meetings highlighted important issues for agencies that are charged with service commissioning and delivery.

The plan for the North West was divided into three parts or phases:

- Arrangements for the initial reception of the refugees at the port of entry (Manchester Airport)

- Arrangements to provide care for the refugees and to integrate the refugees into the social fabric of the local communities

- Arrangements for the safe return of the refugees to Kosovo when the conditions for return are judged to be right by the United Kingdom government and the UNHCR

Arrangements for the initial reception of refugees at the port of entry (Manchester Airport)

These arrangements put in place followed discussions with the key agencies with a part to play in this phase of the operation. The most immediate concern was to ensure that the medical needs of the new arrivals were attended to, taking into account the nature and urgency of the medical need.

The HEPA had established an effective communication with a Department of Health doctor who was seconded to work with the UNHCR in Macedonia. The Department of Health doctor was able to provide the HEPA with advance information about the numbers of refugees likely to arrive on the incoming flight. In addition the HEPA was also able to obtain information from the Department of Health doctor about the medical condition of the refugees on the flight.

Arrangements were put in place to provide emergency first aid assistance to the refugees once the aircraft had touched down. An ambulance was also on standby to provide safe transfer to the local hospital. The port health staff conducted the routine screening for communicable diseases. The refugees were then transported to a civic centre (situated about a mile from the airport). The arrangements for the reception of refugees at the civic centre were put in place by Manchester City Council. The arrangements were designed to:

- Ensure that the refugees were met in warm, cheerful and friendly surroundings

- Ensure that access to the reception was limited to those who had an agreed and defined part to play on the day

- Meet the immediate primary health care needs of the refugees 
- Ensure that the essential formalities were conducted in a sensitive and efficient manner

- Ensure that the initial social and housing needs were assessed

- Ensure that the regions voluntary sector was able to make its contribution

- Ensure that there was no media intrusion at the reception centre

- Ensure that the refugees were transferred from the reception centre to their initial accommodation in a safe and efficient manner

The staff and volunteers at the reception centre were briefed about the recent history of the former Yugoslavia and the origin of the conflict leading to the Kosovors of Albanian origin becoming refugees and fleeing to Macedonia for their physical safety. It was agreed that in view of the known negative experiences of the refugees of the police and the army in Kosovo, the police numbers at the reception centre would be kept to a minimum and further, that if possible the police should provide officers not in uniform for the reception centre. The Refugee Council ensured that interpreters were available in adequate numbers at the reception centre. Manchester Health Authority provided the reception centre with the services of general practitioners registered with it. At all times there was at least one general practitioner at the reception centre to attend to the primary health care needs of the refugees. The general practitioner was supported by a nurse. The children's needs were accommodated by the play leaders from the Manchester City Council. The refugees on arrival at the reception centre were welcomed by a senior officer from Manchester City Council. The refugees were then provided with a hot meal on arrival before any formalities took place. The local branches of the British Red Cross played a central part welcoming the refugees at the reception centre. They brought clothes and essential toiletries for the refugees. The local and health authorities that were designated to act as hosts for refugees arriving on specified flights brought their own officers to the reception centre. These officers used this opportunity to assess the housing, social and health care needs of the refugees. They also travelled with the refugees to their initial destination.

After each completed reception operation there was a full debriefing with the aim of incorporating any important lessons into the following reception exercises.

\section{Arrangements to provide care for the refugees and to integrate the refugees into the social fabric of the local communities}

This part of the arrangements to some extent devolved to the local partners. A number of meetings were held with the office of the Regional Director of Public Health to ensure that the variations in practice were not undesirably uneven. The key issues that needed to be tackled at this stage are discussed below
HEALTH

The key tasks for the health service sector were agreed to be:

- Help with registering with general practitioners, dentists and opticians

- Information about the health care system

- Awareness raising among general practitioners and hospital consultants of cultural factors, unfamiliar conditions and medical problems arising from experiences as refugees, for example, torture and other physical abuse, rape and other forms of sexual abuse, malnutrition, exposure, shrapnel and gunshot injuries and disorders relating to possible use of chemical weapons

- Specialist provision of practitioners experienced in treated trauma related mental health problems

- Care of pregnant women

- Vaccinations programmes

- Care for children

- Advocacy and interpreting

Each health authority has an executive officer named Director of Public Health, who advises the authority of commissioning issues. The office of the Regional Director of Public Health is closely linked to the networks of the region's Directors of Public Health. The link enabled the Regional Director of Public Health to have a degree of influence on the actions of the health authorities in this area.

\section{SOCIAL AND COMMUNITY CARE}

The local authorities traditionally take the lead in this area. The local authorities took steps to raise awareness of the care providers in the following areas:

- Mental health

- Physical disabilities

- Sensory impairments

- Older people

- Learning disabilities

- Support for carers

- Drug, alcohol misuse

The local authorities made arrangements to enable the refugees to have access to Albanian organisations in the United Kingdom and to Albanian newspapers (these were accessed via the internet).

The local authorities also made arrangements to attend to the recreational and leisure needs of the refugees. Football matches, visits to leisure centres and visits to cinemas were arranged for those who wished to take advantage of these.

\section{HOUSING}

The local authorities again took the lead in making this provision. The key principles were agreed with the Refugee Council. The Refugee Council was charged with approving all the accommodation offered to the refugees. Apart from the physical condition of the properties offered to the refugees the following principles were followed:

- The allocation practices need to be flexible

- Housing allocation needs to take account of social networks, family size and family ties

- Refugees may need to be clustered in some areas 
- Housing arrangements should take account of the services available in the area

- The safety of the refugees should be taken into account when an allocation is made

The local authorities made efforts to involve the refugees in the running of the reception centres and in many instances the refugees themselves took over the running of the catering arrangements.

EDUCATION AND CHILDREN

The key issues tackled in this area were:

- Information for parents about education in the United Kingdom

- Access to special needs provision as defined for the general population

- Parent/school liaison, including interpreting

- Awareness raising and training for schools on needs of refugee children

- Language support

- Awareness raising for relevant agencies on needs of refugee children

A number of other related issues may need to be addressed in the future should some of the refugees remain the United Kingdom for longer than 12 months. These relate to education and training for future employment in the United Kingdom.

Arrangements for the safe return of the refugees to Kosovo when the conditions for return are judged to be right by the United Kingdom government and the UNHCR

At a UNHCR meeting in Geneva on the 12 July 1999 there was general consensus among those countries who received Kosovar refugees that the return programme should be coordinated through the UNHCR and International Organisation for Migration.

The Regional Director of Public Health was instrumental in initiating a fact finding visit to Kosovo. This visit was undertaken by the team of four experienced and high ranking officials. They produced a report that was submitted to the EPCU. The team looked at the future reconstruction and development needs of the health care system in Kosovo.

The Regional Director of Public Health is establishing links between medical schools and other higher education institutions in the North West region of the United Kingdom and the equivalent institutions in Kosovo. Healthcare workers among the Kosovo refugees are being asked by the Regional Directors of Public Health about their training needs. It is anticipated that once these needs have been assessed a series of seminars to meet these needs will be organised.
In addition the role of the local agencies in the preparation for the return of refugees to Kosovo is being discussed in the region.

\section{Conclusion}

The was the first major United Kingdom government led operation to take refugees into the United Kingdom since the Ugandan Asians were accepted in the United Kingdom. Then as now, the leadership from the national government was important in ensuring that the administrative system functioned to meet the needs of the refugees. It is often stated that the Ugandan Asians have prospered in the United Kingdom. It may be that the success of the initial reception operation may have a bearing on the integration of a refugee population into the host community.

The key to the success of the present operation, apart from the leadership provided by the central government, was that at the Centre the EPCU was able to ensure that the health and social care system was quickly mobilised into action. The Health Service Circular had considerable impact on the managers and health care professionals on the ground. The EPCU was established to provide the Department of Health input into emergency situations. On this occasion it was clearly effective. It should be remembered however that the number of refugees accepted into the United Kingdom was relatively small.

In the North West the HEPA's networks proved to be robust. The emergency planning system in the region was able to adapt to meet the needs of a group of people whose needs and culture it was not entirely familiar to it. This is partly because in the region a great emphasis is placed on the professionals acquiring transferable skills. The preparations before the arrivals of refugees into the United Kingdom also helped to ensure that a leap into the dark was avoided.

It is important that in a world that is becoming more integrated and interdependent we are able to respond to those in need.

First they came for the Jews and I did not speak out because I was not a Jew Then they came for the communists and I did not speak out because I was not a communist

Then they came for the trade unionists and I did not speak out

because I was not a trade unionist

Then they came for me

and there was no one left

to speak out for me

Pastor Niemoeller 